\title{
Fundamentos y génesis de la cuestión social: acumulación originaria, patriarcado y conquista
}

\author{
Foundations and genesis of the social question: \\ primitive accumulation, patriarchy and conquest
}

\author{
Manuel Waldemar Mallardi \\ Lic. y Mag. en Trabajo Social y Dr. en Ciencias Sociales. Profesor en la Carrera de Trabajo \\ Social-FCH-UNICEN, de Tandil, Argentina. Investigador Asistente CONICET. \\ manuelmallardi@yahoo.com.ar
}

\begin{abstract}
Resumen: El presente texto pretende aportar a las discusiones contemporáneas acerca de las determinaciones histórico sociales de la "cuestión social" en la sociedad capitalista. A partir de recuperar el estudio realizado por Marx sobre la "acumulación originaria" se avanza en la recuperación de la relación existente entre clases sociales, patriarcado y la conquista de América.
\end{abstract}

Palabras clave: Cuestión social. Capitalismo. Patriarcado. Conquista.

\begin{abstract}
The aim of this text is to contribute to the contemporary discussions about the historical and social determinations of the "social question" in capitalist society. From recovering the study by Marx on the 'primitive accumulation' it is advanced in the recovery of the relationship between social classes, patriarchy and the conquest of America.
\end{abstract}

Keywords: Social question. Capitalism. Patriarchy. Conquest.

\section{Introducción}

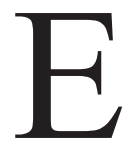

1 presente texto pretende sintetizar un conjunto de reflexiones en torno a las determinaciones histórico sociales de la "cuestión social" en la sociedad capitalista. Frente a posturas que interpelan el abordaje marxista sobre la "cuestión social", señalando que estas aproximaciones no reconocen otras formas de dominación presentes en la sociedad capitalista, tales como el patriarcado, el racismo y la violencia ejercida sobre los pueblos aborígenes en la región, la aproximación realizada es enriquecida a partir de la consideración de relaciones sociales 
donde la opresión de distintos sectores de la sociedad se articula y refuerza con la explotación capitalista.

La importancia de profundizar el debate en torno a los fundamentos de la desigualdad radica en la necesidad de avanzar en la comprensión de sus expresiones contemporáneas, donde la lógica del capital reifica al extremo las relaciones sociales y, en muchos casos, asocia conquistas particulares con sus necesidades de valorización.

Cabe señalar, que el presente texto no pretende ni persigue un intento de reconstrucción histórica de los procesos considerados, sino comprender los trazos generales que explican social e históricamente la articulación dialéctica entre los mecanismos de explotación y opresión en el modo de producción capitalista.

\section{Acumulación originaria, explotación y mecanismos de opresión}

En el marco de la recuperación de los aspectos ontológicos e histórico concretos del trabajo, se aborda el estudio de la "cuestión social" a partir de las contradicciones que se generan como consecuencia de la coexistencia contradictoria de las clases antagónicas que representan al capital y al trabajo. ${ }^{1}$ De este modo, se considera que la "cuestión social" presenta cuatro características fundamentales: es producto de la instauración del modo de producción capitalista; supone una tendencia total que afecta de manera particular y diferenciada a distintos sectores de la población; implica el empobrecimiento de la clase trabajadora en relación con el enriquecimiento de los sectores capitalistas, y es consecuencia de la movilización y reivindicaciones de distintos sectores y fracciones que suponen el pasaje de una clase trabajadora con conciencia en-sí a para-sí, es decir, la conformación de un actor político fundamental en la sociedad burguesa (Mallardi, 2015).

Sobre esta base, se afirma que la sociabilidad burguesa genera un marco de contradicciones y antagonismos capaz de desarrollar en un mismo proceso el enriquecimiento de unos y el empobrecimiento de otros, por lo cual, se ubica la génesis de la "cuestión social" en la sociedad burguesa en el carácter colectivo de

1. Para profundizar sobre dicha categoría desde esta perspectiva ver Iamamoto, 1997 y 2004; Netto, 2002, 2002b y 2003; Pimentel, 2007. 
la producción en contraposición a la apropiación privada de la propia actividad humana (Iamamoto, 2007).

El sistema capitalista, a diferencia de los modos de producción anteriores, requiere la presencia de dos clases sociales: los poseedores del dinero y de los medios de producción y subsistencia, por un lado, y los dueños de la fuerza de trabajo, por el otro: "trabajadores libres" dispuestos a insertarse cotidianamente en el mercado de trabajo. Esta exigencia del modo de producción capitalista, predominante en las sociedades contemporáneas, no es natural ni ahistórica, sino el resultado de procesos económicos, sociales y políticos que Marx denominó como acumulación originaria. La conquista, el sojuzgamiento, el homicidio motivado por el robo, en síntesis, la violencia, tuvieron un rol fundamental en el punto de partida de la sociedad capitalista y constituyeron la base para instalar relaciones de producción y reproducción fundadas en la alienación y la explotación del hombre por el hombre.

Recuperar estos análisis y enriquecerlos a la luz de aportes de autores que han profundizado la indagación en torno a las particularidades de la acumulación originaria se torna fundamental para comprender las múltiples determinaciones de la explotación capitalista y su contradictoria articulación con mecanismos de opresión de género, vinculado al patriarcado, y al racismo, heredero de la esclavitud en las sociedades precapitalistas. ${ }^{2}$ En este sentido, se recupera la articulación dialéctica entre la explotación, aquélla relación entre las clases que hace referencia a la apropiación del producto del trabajo excedente de las masas trabajadoras por parte de la clase capitalista, con la opresión, en tanto sometimiento basado en razones culturales, raciales o sexuales (D’Atri, 2004; Souza, 2015).

En este marco, el texto que aquí se propone persigue la finalidad de establecer los trazos generales que permiten comprender cómo mecanismos de opresión preexistentes al capitalismo adquieren una funcionalidad determinada en el proceso de acumulación originaria y establecen una subsunción de los mismos a la lógica del capital. En tanto aproximación a tales fundamentos, en primer lugar se establecen los principales rasgos de la acumulación originaria y las implicancias de la ley general de acumulación capitalista para la reproducción de la explotación, para luego

2. Para un análisis de la lógica contradictoria de la relación entre capitalismo, patriarcado y racismo, ver Saffioti, 2000. 
puntualizar en los mecanismos de opresión patriarcal y las implicancias de la conquista americana, identificando las tendencias que articulan uno y otros procesos.

\subsection{Acumulación originaria, explotación y ley general de acumulación capitalista}

Para Marx, el capital requiere la separación de los trabajadores y la propiedad de los medios de producción, por lo cual la acumulación originaria es el proceso histórico que realiza dicha escisión y expulsa a los trabajadores a enfrentarse sin más elementos que su fuerza de trabajo a los designios del capital. La base de esta acumulación la constituye, para el pensamiento marxiano, la expropiación que despoja de la tierra al trabajador, proceso mediante el cual se separa a grandes masas de la población de sus medios de subsistencia.

Mientras que durante los siglos XIV y XV predominaba la presencia de campesinos que cultivaban la tierra, en el marco de las relaciones propias del modo de producción feudal, como así también hacían usufructo de tierras comunales, ${ }^{3}$ a inicios del siglo XVI se produce un proceso de expulsión de la tierras feudales y usurpación de las comunales, provocando la emigración de los campesinos a las ciudades y, en consecuencia, se aumentan las filas del proletariado. Paralelamente, ante la imposibilidad de producir los bienes necesarios para la reproducción, un número mayor de la población se ve obligado a adquirir dichos bienes en el mercado, generando mayor demanda de manufacturas.

La consecuencia directa de estos procesos se expresa en una creciente pauperización de la población, en tanto que ante la expulsión de las tierras no existía la posibilidad de ser absorbidos de manera inmediata por la naciente industria, como así tampoco podían adaptarse inmediatamente a las nuevas exigencias de la ciudad. Frente al aumento del número de mendigos, ladrones y vagabundos, las respuestas de los sectores dominantes profundizaron la coerción y la represión, con penas que iban desde el trabajo forzado, el castigo físico a quitarle la vida al acusado de "delincuente voluntario". Al respecto, sintetiza Marx

la población rural, expropiada por la violencia, expulsada de sus tierras y reducida al vagabundeo, fue obligada a someterse, mediante una legislación terrorista y grotesca

3. Sobre las particularidades del modo de producción feudal ver Hill, 1977 y Hilton, 1978 y 1988. 
y a fuerza de latigazos, hierros candentes y tormentos, a la disciplina que requería el sistema del trabajo asalariado. (Marx, 2009c, p. 922) ${ }^{4}$

Recuperando procesos históricos de este período, Fedirici (2015) menciona ejemplos de asesinatos, torturas y empalamientos orientados a quebrantar la resistencia de los trabajadores, quienes buscaban dejar atrás la servidumbre y la esclavitud. Al respecto, menciona que la respuesta de los sectores dominantes articuló la concentración de la tierra y la introducción del trabajo asalariado forzoso. En la misma línea, Thompson (2012) muestra como desde la génesis parasitaria del capitalismo en el feudalismo, la pauperización y el disciplinamiento de la población se llevo a cabo mediante la violencia: todo tuvo lugar a la sombra de la horca.

En este proceso, la historiadora italiana señala las implicaciones que la privatización de la tierra tuvo para los sectores trabajadores europeos, expropiación que se realizó mediante la expulsión de inquilinos, aumento de las rentas e impuestos por parte del Estado, en articulación con la guerra y la reforma religiosa. Además, destaca el proceso de "cercamientos" de tierras comunales, mediante la abolición del sistema de campo abierto y la expulsión de aquellos que no tenían tierra y sobrevivían ahí. ${ }^{5}$

Se generan entonces las condiciones materiales y políticas para el desarrollo del capitalismo, que hasta entonces solo podía desarrollarse con expresiones parasitarias en la economía feudal, en tanto la estructura social y económica precapitalista no les dejaba campo de acción suficiente (Hobsbawm, 1988). Sin entrar en detalles en torno a los procesos sociales que materializaron la Revolución Industrial y, con ella la consolidación del modo de producción capitalista, interesa resaltar el impacto en las condiciones de vida de amplios sectores de la población, en tanto se

4. El autor continúa planteando que "no basta con que las condiciones de trabajo se presenten en un polo como capital y en el otro como hombres que no tienen nada que vender, salvo su fuerza de trabajo. Tampoco basta con obligarlos a que se vendan voluntariamente. En el transcurso de la producción capitalista se desarrolla una clase trabajadora que, por educación, tradición y hábito reconoce las exigencias de ese modo de producción como leyes naturales, evidentes por si mismas. La organización del proceso capitalista de producción desarrollado quebranta toda resistencia; la generación constante de una sobrepoblación relativa mantiene la ley de la oferta y la demanda del trabajo, y por tanto el salario, dentro de los carriles que convienen a las necesidades de valorización del capital" (Marx, 2009c, p. 922).

5. Para un análisis del proceso de cercamiento y sus implicancias en la sociedad feudal europea ver, además de los autores mencionados, el trabajo de Campagne, 2005. 
consolida la mercantilización de la fuerza de trabajo. ${ }^{6}$ Claramente Marx describe esta situación al afirmar que el proceso de trabajo en el modo de producción capitalista, donde el capitalista adquiere la fuerza de trabajo del trabajador como mercancía, implica dos fenómenos peculiares. Por un lado, el obrero trabaja bajo control del capitalista, a quien le pertenece el trabajo de aquél, y, por el otro, en consecuencia, el producto es propiedad del capitalista, no del obrero que lo produjo. Dice el pensador alemán:

desde el momento en que el obrero pisa el taller del capitalista, el valor de uso de su fuerza de trabajo, y por tanto su uso, el trabajo, pertenece al capitalista. Mediante la compra de la fuerza de trabajo, el capitalista ha incorporado la actividad laboral misma, como fermento vivo, a los elementos muertos que componen el producto, $\mathrm{y}$ que también le pertenecen. (Marx, 2009a, p. 225)

Entonces, la mercantilización de la fuerza de trabajo de un trabajador "libre" y la extracción del plusvalor, parte excedente del trabajo apropiada por el capitalista, constituyen aspectos sustanciales del nuevo modo de producción. Además, a partir de este momento, la relación del hombre con la naturaleza se ve permanentemente revolucionada, por el constante aumento de la tecnología en la producción. Ahora bien, en este contexto, cuando quizás por primera vez en la historia el hombre tiene la posibilidad de producir los bienes necesarios para la reproducción de la humanidad, la persistencia de la pobreza y el hambre adquiere un nuevo significado social e histórico.

Nuevamente Marx, en el capítulo XXIII de El Capital, nos da elementos para comprender la ley general de acumulación capitalista, según la cual en el capitalismo es necesario pensar relativamente los aspectos constitutivos de una misma totalidad, siendo, para la situación analizada, el proceso de enriquecimiento de unos por un lado, y el proceso de empobrecimiento de otros, por otro. Implica que la ponderación relativa del capital variable en el proceso de producción en relación con el capital constante sufre modificaciones y fluctuaciones que van en detrimento del poseedor de la fuerza de trabajo. En principio plantea que

6. Sobre los procesos que caracterizaron la revolución industrial, ver Hobsbawm, 1987, 1988 y 2007 y Thompson, 2012. 
el propio mecanismo del proceso de acumulación, al acrecentar el capital, aumenta la masa de los "pobres laboriosos", esto es, de los asalariados que transforman su fuerza de trabajo en fuerza creciente de valorización al servicio del creciente capital, y que por tanto se ven obligados a perpetuar la relación de dependencia que los liga a su propio producto, personificado en el capitalista. (Marx, 2009c, p. 763)

La consolidación del proceso de producción capitalista lleva a que en el mismo proceso aumente la importancia de los medios de producción a la vez que disminuye la de la fuerza productiva. Consecuentemente, plantea Marx, el mayor peso de los medios de producción sobre la fuerza de trabajo produce que se reduzca progresivamente el número de trabajadores necesario. Avances en los medios de producción entonces constituyen la base para las condiciones de expulsión de trabajadores del proceso de trabajo, proceso que se desarrolla de forma progresiva en perjuicio del capital variable. La reducción del tiempo socialmente necesario para la producción de mercaderías, por un lado, amplía el tiempo de trabajo excedente, mientras que por el otro promueve la tendencia a la expulsión de trabajadores del proceso de producción.

La consecuencia directa de este proceso consiste en la creación constante de un importante sector de la población que se encuentra marginado del proceso de producción, es excedente y superfluo al proceso de valorización; población que tiene una importancia vital para la continuidad del modo de producción capitalista, en tanto pasa a constituir parte del denominado ejército industrial de reserva, dispuesto a ingresar cuando el capitalista lo requiera, pues se constituye en "el material humano explotable y siempre disponible, independientemente de los límites del aumento real experimentado por la población” (Marx, 2009c, p. 786-787).

Condición vital del modo de producción capitalista, la producción de una población excedente relativa es la base para la profundización de los procesos de extracción del trabajo excedente, el disciplinamiento de los trabajadores ocupados y la implementación de nuevas formas de trabajo que van en detrimento de conquistas y protecciones adquiridas. ${ }^{7}$ Durante los períodos de prosperidad, la demanda

7. Así, por ejemplo, "durante los períodos de estancamiento y de prosperidad media, el ejército industrial de reserva o sobrepoblación relativa ejerce presión sobre el ejército obrero activo, y pone coto a sus exigencias durante los períodos de sobreproducción y de paroxismo. La sobrepoblación relativa, pues, es el trasfondo sobre el que se mueve la ley de la oferta y la demanda de trabajo. Comprime el campo de acción de 
de trabajo hace que parte del ejército de reserva sea absorbida en la fuerza de trabajo, manteniendo así bajos los salarios; mientras que en tiempos de crisis, se constituye en un recurso siempre disponible de trabajo barato que inhibe cualquier intento de la clase obrera para mejorar su suerte (Giddens, 1994).

Estas tendencias alteran la totalidad de la reproducción social, imponiendo una nueva red de relaciones sociales, de un nuevo ritmo de vida y de trabajo, acentuando, principalmente, la diferenciación entre las clases y haciendo del movimiento de valorización del capital el movimiento fundamental de la sociedad burguesa. La alteración de la reproducción social afecta las múltiples esferas de la vida cotidiana de las clases sociales y recupera y redefine el significado social e histórico que distintas formas de opresión tenían hasta el momento.

\subsection{Acumulación originaria, patriarcado y opresión de las mujeres}

Analizando el proceso de acumulación originaria, Fedirici (2015) incorpora el papel que significó el sometimiento de las mujeres para la reproducción de la fuerza de trabajo, lo que tornó necesario instalar al interior de los sectores trabajadores diferencias y divisiones jerárquicas construidas a partir del género. En consecuencia, este punto obliga a articular el proceso de acumulación originaria capitalista con el desarrollo del patriarcado.

$\mathrm{Al}$ respecto, la bibliografía especializada da muestras acabadas que permiten ubicar al patriarcado como un mecanismo de opresión de las mujeres previo al surgimiento del modo de producción capitalista (Engels, 2007; Lerner, 1990; Eisenstein, 1980; Young, 1992), aunque esto no lleva a afirmar que él mismo tiene un carácter ahistórico y universal, sino que, como relación social, tiene una génesis y un desarrollo que le permite adquirir distintas expresiones en el marco de las particularidades de la reproducción social. Así, por ejemplo, la opresión de las mujeres adquiere una funcionalidad determinada en el modo de producción capitalista, la cual presenta continuidades y rupturas con respecto al feudalismo. Estas particularidades llevan a afirmar la presencia de un patriarcado capitalista (Eisenstein, 1980) cuyas características se trabajarán en la continuidad del trabajo.

esta ley dentro de los límites que convienen de manera absoluta al ansia de explotación y el afán de poder del capital" (Marx, 2009c, p. 795). 
En la recuperación de los fundamentos del patriarcado, dentro de una perspectiva histórico crítica, el trabajo de Engels El origen de la familia, de la propiedad privada y del Estado del año 1884 constituye un aporte fundamental para romper con la mirada ahistórica de la familia en el pensamiento burgués. Este texto, con elementos analíticos superados a partir del necesario avance de la producción de conocimiento, brinda aportes centrales para comprender tanto la relación entre la familia y el modo de producción capitalista, como entre estos dos aspectos y el patriarcado como sistema de dominación de las mujeres. ${ }^{8}$

En esta obra, Engels, recuperando los aportes de Morgan, parte de considerar a la familia como un elemento activo, cuyo desarrollo se vincula a la reproducción de la sociedad. Por lo tanto, frente al pensamiento burgués que tiende a negar el carácter social e histórico de los procesos sociales y por lo tanto promueve su reificación, Engels tiene en la obra de Morgan un punto de partida fundante para la consolidación de una perspectiva materialista sobre la historia de la familia.

Sobre esta base, la constatación de diferencias sustanciales en los sistemas de parentesco y en la configuración de las relaciones familiares conllevó a recuperar el carácter sociohistórico de la familia, reconstruyendo sus trazos históricos; reconstrucción realizada con el fin de identificar aquellos procesos que llevaron desde la tribu, con sociedades matrilineales o matrilocales a la actualidad, donde prima la familia monogámica y la opresión de las mujeres. Con énfasis en distintos procesos históricos Engels (2007), Meillassoux (1985), Lerner (1990) y Lessa (2012) ponen en evidencia la existencia de sociedades donde la opresión de los hombres para con las mujeres no existía en los términos generalizados que el patriarcado demanda, e identifican aquellos procesos significativos que fueron instalando dicha desigualdad en la reproducción social.

En este punto, se identifica en la sexualidad y en la capacidad reproductiva de las mujeres un aspecto crucial para la instauración del patriarcado, no porque ello remita a una biologización de la opresión, sino por las implicancias económicas, políticas y culturales que la sociedad le fue dando a tal capacidad. Es decir, como afirma Eisenstein (1980), son las relaciones de producción y reproducción las que

8. Algunas consideraciones en torno a la vigencia de los aportes de Engels, su incidencia en los estudios sobre la familia en general y las mujeres en particular y los puntos que merecen revisión se pueden encontrar en: Goldman, 2010; Ciriza, 2007; Lerner, 1990 y Netto, 1997. 
determinan las relaciones que las mujeres tienen consigo mismas y con la sociedad como seres reproductores y no una cuestión abstracta asociada a la biología. ${ }^{9}$

En términos generales, las reconstrucciones realizadas por los distintos autores identifican procesos donde la organización familiar es atravesada paulatinamente por cambios en la producción de los bienes de uso, donde se incorpora la domesticación de animales y la cría de ganados, promoviendo el paso del nomadismo al sedentarismo. La vida comunitaria es reemplazada por la familiar, donde las riquezas pasaron a convertirse en propiedad familiar. Estas alteraciones en la producción y reproducción de la sociedad pusieron en tela de juicio prácticas y costumbres familiares, vinculadas, principalmente, a la herencia y al papel de las mujeres en la sociedad.

Producto de procesos históricos, cuyo desarrollo escapa a los fines del presente trabajo, surge la familia patriarcal, caracterizada por la organización familiar bajo el poder paterno del jefe de ésta. La patria potestad paterna otorga al hombre el poder total en las decisiones vinculadas al ámbito doméstico, llegando a tener el derecho a la vida y muerte de todos sus miembros, al igual que con sus esclavos. Dice Engels al respecto: "para asegurar la fidelidad de la mujer, y por consiguiente la paternidad de los hijos, es entregada aquélla sin reservas al poder del hombre; cuando éste la mata, no hace más que ejercer su derecho" (Engels, 2007, p. 64). Comienzan a consolidarse, de este modo, los fundamentos de la familia moderna, la cual se funda en el patriarcado como sistema de dominación de los hombres para con las mujeres, en primer lugar, y para con los hijos, por extensión.

Ahora bien, teniendo en cuenta estos aspectos, se torna necesario identificar los trazos generales de los mecanismos por los cuales la opresión de las mujeres pudo consumarse y tornarse hegemónica en la reproducción social. Al respecto, lejos de ser procesos armónicos y lineales, se trató de un "esclavizamiento de un sexo por el otro" (Engels, 2007), donde la resistencia de las mujeres fue salvajemente reprimida y cercenada. En este punto, los aportes de Fedirici (2015) son sustanciales para comprender los procesos de resistencia que emprendieron las mujeres, como así también la violencia ejercida sobre ellas mediante la "caza de brujas".

9. Analizando la división del trabajo por género Young afirma que ni “una explicación biológica, ni una psicológica pueden demostrar, por ejemplo, cómo los hombres de una determinada sociedad ocupan en ella, una posición de superioridad institucionalizada. Los hombres pueden ocupar esa posición solo si la organización de las relaciones sociales que surgen de la actividad laboral les otorga un cierto grado de control sobre, y acceso a los recursos que las mujeres no lo tienen" (1992, p. 9). 
Partiendo de considerar la necesidad de relacionar la historia de las mujeres con las luchas que libró el proletariado medieval europeo contra el poder feudal en todas sus formas, Fedirici analiza las principales formas de resistencia de los campesinos y destaca el papel de las mujeres en las resistencias cotidianas a la servidumbre y la explotación. Asimismo, la historiadora demuestra los mecanismos desarrollados por todas las fuerzas del poder feudal - nobleza, iglesia y la burguesía - tendientes a contrarrestar estas resistencias y apropiarse de nuevas fuentes de riqueza. La privatización de la tierra y los cercamientos, proceso arriba mencionado, tuvo un impacto significativamente mayor en el cotidiano de las mujeres, principalmente por las dificultades adicionales que implicaba vagabundear o migrar (mayor posibilidad de ser víctimas de violencia masculina, además de las dificultades generadas por el embarazo y el cuidado de niños) y la imposibilidad de unirse a los ejércitos.

Como consecuencia de los cercamientos y la mercantilización de las relaciones sociales, las mujeres, además, encontraron mayores dificultades para mantenerse, siendo confinadas

al trabajo reproductivo en el preciso momento en que este trabajo se estaba viendo absolutamente devaluado [...] En el nuevo régimen monetario, sólo la producción para el mercado estaba definida como actividad creadora de valor, mientras que la reproducción del trabajador comenzó a considerarse algo sin valor desde el punto de vista económico, e incluso dejó de ser considerada un trabajo (Fedirici, 2015, p. 130).

Se inauguraron entonces largos períodos de hambruna, no de escasez de alimentos, seguidos por distintas expresiones de lucha por la comida y, consecuentemente en un capitalismo naciente, mecanismos coercitivos de disciplinamiento y represión. Al respecto, Thompson (2012) menciona que en la segunda mitad del siglo XVIII aumentó significativamente el número de delitos penados con la muerte, destacándose aquellos vinculados a los reclamos por mejores condiciones de vida en general y al acceso a los alimentos en particular. Esta criminalización evidencia la resistencia de los sectores trabajadores a la explotación existente, donde se destacan los motines de subsistencia, donde las mujeres tenían un papel protagónico, orientados a acceder a los alimentos indispensables para la reproducción cotidiana, frente a la especulación y el aumento desenfrenado de precios.

Además de la criminalización estatal sobre las protestas y luchas de los trabajadores, producto de la pobreza extrema y el hambre, la muerte cayó sobre los 
"pobres", por intermedio de plagas y enfermedades que provocaron una crisis demográfica que puso en jaque la economía naciente. Por la baja poblacional comenzó a perseguirse a la población pobre acusada de rehusarse a reproducirse, pero principalmente se avanzó en el control del cuerpo de las mujeres con el fin de regular la procreación y quebrar el control de las mujeres sobre la reproducción. En este punto, la historiadora italiana menciona que esta guerra "fue librada principalmente a través de la caza de brujas que literalmente demonizó cualquier forma de control de la natalidad y de sexualidad no procreativa, al mismo tiempo que se acusaba a las mujeres de sacrificar niños al Demonio" (Fedirici, 2015, p. 158). ${ }^{10}$ Como consecuencia de esta intervención estatal sobre la reproducción, continúa la autora, grandes cantidades de mujeres fueron procesadas por infanticidio y brujería, terminando casi inevitablemente en la muerte. Mediante la persecución, la tortura, la hoguera y otras formas de disciplinamiento, se instaló la esclavización de las mujeres a la procreación y, en consecuencia, ésta pasó a ser su principal función social en la acumulación capitalista. En consecuencia, el cuerpo de las mujeres se transformó en un instrumento para la reproducción de la fuerza de trabajo, respondiendo a exigencias de la reproducción social.

Analizando el impacto del capitalismo en la vida cotidiana de las mujeres, Hobsbawm (2007b) menciona dos cuestiones centrales. En primer lugar, el impacto de la "protoindustrialización", asociado al crecimiento de las industrias domésticas, donde las mujeres tuvieron una participación significativa, en tanto les permitió vender su fuerza de trabajo al mismo tiempo que podían realizar las actividades del hogar y el cuidado de los hijos. ${ }^{11}$ En segundo lugar, menciona que el proceso de industrialización produjo la separación del hogar del puesto de tra-

10. Por ejemplo, la autora menciona que "se adoptaron nuevas formas de vigilancia para asegurar que las mujeres no interrumpieran sus embarazos. En Francia, un edicto real de 1556 requería de las mujeres que registrasen cada embarazo y sentenciaba a muerte a aquellas cuyos bebés morían antes del bautismo después de un parto a escondidas, sin que importase que se las considerase culpables o inocentes de la muerte" (Fedirici, 201, p. 159). Más adelante agrega que "la definición de las mujeres como seres demoníacos y las prácticas atroces y humillantes a las que muchas de ellas fueron sometidas dejó marcas indelebles en su psique colectiva y en el sentido de sus posibilidades. [...] Pues la caza de brujas destruyó todo un mundo de prácticas femeninas, relaciones colectivas y sistemas de conocimiento que habían sido la base del poder de las mujeres en la Europa precapitalista, así como la condición necesaria para su resistencia en la lucha contra el feudalismo" (Fedirici, 2015, p. 183-184).

11. Debe tenerse en cuenta que pese a la importante participación de las mujeres en el ámbito de las industrias domésticas, generalmente el salario era administrado por el hombre, reforzando su dominación patriarcal (Fedirici, 2015). 
bajo, teniendo como consecuencia la exclusión de las mujeres de la economía reconocida públicamente y su dependencia del trabajo asalariado del hombre.

Surge así una de las particularidades del patriarcado capitalista: la separación entre lo público y lo privado, correspondiendo a los hombres el primero, asociado al mundo laboral, y a las mujeres el segundo, el espacio doméstico, del ámbito familiar. Consecuencia de estos procesos, las mujeres aparecen asociadas al ideario de esposa obediente y las tareas a las que es destinada son vistas como no trabajo, como algo a lo que naturalmente estaba destinada. ${ }^{12}$

Ahora bien, es importante mencionar que los autores consultados coinciden en mencionar que más allá de este ideario instalado en y por la sociedad capitalista, donde las mujeres son reducidas al ámbito del hogar y las responsabilidades familiares, su exclusión del mercado del trabajo no es total. Distintos factores complementarios inciden para que ello resulte de tal manera. En primer lugar, dado que muchos varones no lograban garantizar los ingresos necesarios para la reproducción cotidiana, se tornaba necesario el ingreso al mercado laboral de mujeres y niños. Esta venta de la fuerza de trabajo, en segundo lugar, era estimulada por los capitalistas dado que era más barata y más fácil de adaptar a las exigencias y explotación de los patrones. En tercer lugar, el ingreso de la tecnología favoreció la incorporación de mujeres y niños, en tanto la fuerza física dejó de ser condición necesaria para el trabajo industrial.

Teniendo en cuenta estos elementos, más que exclusión de las mujeres del mundo del trabajo, se torna necesario describir esta realidad como procesos de marginalización de las mujeres en estrecha relación con su consideración como fuerza laboral secundaria, siendo parte del ejercito industrial de reserva (Young, 1992). La autora afirma que el capitalismo requiere encontrar criterios que permitan distinguir el núcleo de trabajadores primarios de los trabajadores secundarios o marginales, siendo la ideología patriarcal un aspecto central para dividir la fuerza laboral. En este sentido, menciona que para el siglo XIX las mujeres se encontraban marginadas de la actividad económica, aunque, de acuerdo a las necesidades del

12. Dice Hobsbawm que "la industrialización del siglo XIX (a diferencia de la del siglo XX) tendía a hacer del matrimonio y de la familia la principal carrera de la mujer de la clase trabajadora a la que la pobreza no obligara a buscarse otro trabajo. En la medida en que trabajara por un salario antes de casarse veía en el trabajo asalariado una fase temporal, aunque sin duda deseable, de su vida. Una vez casada, pertenecía al proletariado, no como trabajadora, sino como esposa, madre y ama de casa de trabajadores" (Hobsbawm, 1987, p. 133). 
capital, podía darse su incorporación como bolsa de trabajo a nuevas áreas de la producción como así también con el fin de mantener bajo los salarios. ${ }^{13}$

Se produce, entonces, un proceso complejo de subsunción de la opresión patriarcal a la explotación capitalista, donde las mujeres son doblemente oprimidas: en el ámbito familiar, por el marido, patriarca, jefe de hogar, y en el mercado de trabajo, por la sociedad que utiliza su inserción o no como un mecanismo de regulación de las relaciones con la clase trabajadora.

\subsection{Acumulación originaria, esclavitud y la cuestión indígena}

Además de los procesos arriba mencionados, y en estrecha relación, interesa destacar el señalamiento marxiano en torno a la funcionalidad que adquiere en el proceso de acumulación originaria, la conquista y el exterminio en tierras americanas, indias y africanas. En este sentido, la recuperación de estos procesos históricos, lejos de invalidar la aproximación de la "cuestión social" en tanto capital-trabajo, permite apreciar como la llamada conquista encuentra determinaciones económicas, políticas y sociales en el proceso de transición del feudalismo al capitalismo. Al respecto, Marx sostiene que

el descubrimiento de las comarcas auríferas y argentíferas en América, el extermino, esclavización y soterramiento en las minas de la población aborigen, la conquista y el saqueo de las Indias Orientales, la transformación de África en un coto reservado para la caza comercial de pieles negras, caracterizan los albores de la era de producción capitalista. (Marx, 2009c, p. 939)

13. Coincide D'Atri al afirmar que el capitalismo "aunque ha empujado a millones de mujeres al mercado laboral destruyendo los mitos oscurantistas que la condenaban exclusivamente a permanecer en el ámbito privado del hogar, lo ha hecho para explotarlas doblemente, con salarios menores a los de los varones, para que, de ese modo, pudiera bajar también el salario de los otros trabajadores" (D'Atri, 2004, p. 22). Posteriormente agrega que "las mujeres, por los bajos salarios que se les imponían, constituían más una amenaza que un potencial aliado para los trabajadores varones. Ese fue, históricamente, el rol que la patronal destinó a las mujeres trabajadoras: el de convertirlas en un ejército que presionara objetivamente contra los intereses de los trabajadores varones, compitiendo con sus salarios más bajos por igual tarea que tendía a la baja los salarios del conjunto de la clase o amenazaba, directamente, con la desocupación de la fuerza de trabajo masculina" (D’Atri, 2004, p. 44). Al respecto, consultar Quartim de Moraes, 2003. 
En esta línea, Ianni (1976) afirma que el mismo proceso de acumulación originaria, en tanto proceso estructural e internacional, que creó las condiciones histórico estructurales para la formación del capitalismo industrial en Inglaterra, simultáneamente, forzó la esclavitud en el "nuevo mundo", sea abierta o encubierta, en tanto ésta estaba asociada al comercio de plata, oro, tabaco, azúcar y otros productos coloniales. ${ }^{14}$

Para comprender este proceso y sus particularidades, recuperamos los aportes de Elliot (1990), quien plantea que es necesario comprender el movimiento expansionista de los pueblos ibéricos en el siglo XV en el marco de la realidad particular de Europa en tal contexto, donde todavía se vivían las consecuencias de la peste negra, había escasa oferta de trabajo, los ingresos de los aristócratas habían disminuidos y las fronteras orientales se veían amenazadas por el avance del imperio turco otomano. Además, el movimiento expansionista se explica por la necesidad de desarrollar fuentes alternativas de abastecimiento para artículos de consumo, cuya accesibilidad se estaba tornando dificultosa.

En este marco, la adquisición de nuevas tierras se explica por la necesidad de establecer nuevos mercados, nuevas fuentes de suministro y, por ende, nuevas fuentes de riqueza. ${ }^{15}$ Por ejemplo, para 1460 , los portugueses ya habían penetrado en la costa occidental de África y en el Atlántico, donde la primera se convertía en una fuente potencial de esclavos para trabajar en las plantaciones azucareras que surgían. Esclavismo, conquista, colonización y comercio eran parte de las estrategias de expansión y aumento de la riqueza para ese entonces.

Posterior a la conquista de América, se avanzó en el comercio y la exploración en la búsqueda del oro, donde se procuró afirmar la soberanía, establecer la fe católica, promover la inmigración y el asentamiento y la dominación de tierras y personas (Elliot, 1990). La cantidad de oro no alcanzó a cubrir las expectativas de los españoles, por lo cual la estrategia de Colón, afirma el historiador, sumó el tráfico

14. Sostiene el autor que "en la medida en que se expandía el capital comercial, ampliamente dinamizado por los resultados de los grandes descubrimientos marítimos, es decir, debido a la colonización de nuevas tierras y a la formación de plantaciones, ingenios, haciendas, encomiendas, repartimientos y demás, ocurría en Europa, y principalmente en Inglaterra, la acumulación originaria del capital" (Ianni, 1976, p. 11).

15. Agrega Marx: "La colonia aseguraba a las manufacturas en ascenso un mercado donde colocar sus productos y una acumulación potenciada por el monopolio del mercado. Los tesoros expoliados fuera de Europa directamente por el saqueo, por la esclavización y las matanzas con rapiñas, refluían a la metrópoli y se transformaban allí en capital" (Marx, 2009c, p. 942-43). 
de personas para su venta como esclavos en Europa. Esto, sumado al trabajo forzoso de la población indígena precipitó su extinción.

En la misma línea, Fedirici (2015) afirma que en el "nuevo mundo", mediante los regímenes de la mita y el cuatequil, se sometió a poblaciones aborígenes para la extracción de la plata y el mercurio. Analizando la campaña para maximizar la explotación del trabajo, la autora menciona que el trabajo, las enfermedades y los castigos disciplinarios provocaron la merma de la población originaria. Conquista, saqueos, destrucción y muerte se constituyeron en una constante que acompañaba cada incursión española, ${ }^{16}$ creando en la población nativa una atmósfera de terror religioso provocada por la llegada de los españoles (Wachtel, 1990). ${ }^{17}$

La extracción de riqueza se llevó a cabo, entonces, por la incautación directa de los excedentes de metales o piedras preciosas, previamente acumulados. Cuando dichos excedentes comenzaron a agotarse, la extracción se desarrolló a partir de la explotación directa de la población nativa (MacLeod, 1990). En este punto, el autor destaca que en algunas regiones los invasores encontraron condiciones existentes de esclavitud y servidumbre, por lo cual su accionar estuvo orientado a eliminar a las autoridades previas y usufructuar dichas relaciones preexistentes. Por su parte, en aquellas zonas donde se veía la posibilidad de profundizar la extracción, pero escaseaba mano de obra, el traslado de indígenas esclavos paso a ser la solución. De este modo, el esclavismo pasó a ser el primer sistema laboral en la mayoría de las colonias, el cual luego se transformó en las llamadas encomiendas. ${ }^{18}$

La necesidad de mano de obra esclava, motivó la incorporación de población negra, recuperando la experiencia con una importante trayectoria similar en Europa desde el siglo XIII. Al respecto, Klein (2007) da muestra como en las sociedades

16. Elliot (1990) afirma que el Nuevo Mundo, producto de siglos de aislamiento, fue rápidamente afectado por las enfermedades que traía la población europea. Al respecto, afirma que la conquista de América fue una conquista realizada tanto por microbios como por hombres. Para profundizar al respecto ver Malvido, 2003.

17. Analizando la situación de La Española, afirma Elliot que "a los 20 años de la llegada de Colón, la población de la había sido una isla densamente poblada, desapareció por la guerra, las enfermedades, los malos tratos y el trauma producido por los esfuerzos que hicieron los invasores por adaptarla a unas formas de vida y comportamientos totalmente distintos a su experiencia anterior" (Elliot, 1990, p. 138).

18. Para el análisis del sistema de encomiendas ver Jiménez Abollado, 2000; mientras que para una caracterización de la economía de la sociedad colonial ver Mörner, 1990. Algunos aspectos de las particularidades de la conquista brasilera pueden encontrarse en Schwartz, 1990. 
precapitalistas los europeos cristianos se dedicaban al comercio de esclavos y a la producción agrícola basada en la esclavitud. Con la conquista del continente americano, sostiene el autor, la expansión de mano de obra esclava africana no fue necesaria inmediatamente, pero luego la baja de la población local y la prohibición de la esclavitud indígena promovieron el auge de la incorporación de esclavos africanos. ${ }^{19}$

En síntesis, la explotación del trabajo esclavo estaba subordinada a los movimientos del capital europeo (Ianni, 1976) en tanto la extracción de plusvalía se desarrollaba con una tasa de explotación mucho más alta que la de los trabajadores de Europa (Fedirici, 2015). ${ }^{20}$

Como se puede apreciar, aquí apenas sintetizado, el desarrollo capitalista europeo recibió un impulso fundamental a partir de la conquista de América, por lo cual este proceso no puede ser pensado y analizado de manera escindida de las transformaciones societales europeas de la época. Al respecto, analizando la economía europea del período de la revolución francesa, Hobsbawm (2007) da muestra de la interdependencia con América, en tanto destaca que desde este continente se exportaban productos de minería, como así también azúcar, en menos extensión el tabaco y café, colorantes y, desde el principio de la revolución industrial, el algodón más que nada. Asimismo, considerando la intervención española en América en el siglo XVI, existía la determinación de introducir a los indios en una economía de salarios, entregándoles tierras, así como salarios por su trabajo, de modo que pudieran adquirir productos españoles (Elliot, 1990b).

19. Sobre el impacto de la conquista y la trata de esclavos en la clase trabajadora europea, Fedirici sostiene tales procesos fueron una desgracia, en tanto que "la esclavitud - al igual que la caza de brujas - fue un inmenso laboratorio para la experimentación con métodos de control del trabajo que luego fueron importados a Europa. La esclavitud influyó también en los salarios y en la situación legal de los trabajadores europeos; no puede ser coincidencia que justo cuando terminó la esclavitud, los salarios en Europa aumentaran considerablemente y los trabajadores europeos lograran el derecho a organizarse" (Fedirici, 2015: 188). Por su parte, Williams (2011), partiendo de analizar la esclavitud como un aspecto central en los primeros momentos de la formación del capitalismo mundial y del arranque de la acumulación en Gran Bretaña, muestra la relación existente entre las riquezas de América, los esclavos africanos y el crecimiento europeo.

20. Haciendo un análisis general de las relaciones económicas entre América y Europa, Fedirici plantea que "el sistema de plantaciones fue decisivo para el desarrollo capitalista no sólo por la inmensa cantidad de plusvalor que se acumuló a partir de él, sino porque estableció un modelo de administración del trabajo, de producción orientada a la exportación, de integración económica y de división internacional del trabajo que desde entonces ha sido el paradigma de las relaciones de clases capitalistas" (Fedirici, 2015, p. 186). 
El avance sobre el territorio americano, mediante la conquista, la esclavitud y la muerte, instaló las bases para procesos de explotación que fueron funcionales el modo de producción capitalista, por ello las condiciones de vida de la población nativa se explican a partir de la apropiación del excedente por parte de los europeos. Entonces, la opresión de los pueblos nativos, mediante una consideración que ponía en tela de juicio su calidad de seres humanos, se articuló desde su génesis con la explotación del capitalismo naciente.

\section{Síntesis: "Cuestión Social", tensiones entre mecanismos de explotación y opresión en la sociedad capitalista}

La sociedad capitalista, para su reproducción, supone un conjunto de procesos fundamentales que se tornan en el andamiaje de su existencia y continuidad. Dentro de esos procesos, la mercantilización de la fuerza de trabajo implica cambios substanciales no solo para la producción, sino también para la reproducción social. En consecuencia, amplios sectores de la población deben vender su fuerza de trabajo para adquirir el salario que posibilite garantizar su reproducción cotidiana.

En este marco, distintas relaciones sociales adquieren una funcionalidad social e histórica que se explica a partir de este proceso de mercantilización. Al respecto, reconociendo una trayectoria histórica del patriarcado anterior al capitalismo, se reconoce que el primero adquiere nuevas particularidades a partir de las determinaciones que establece el modo de producción capitalista. Igualmente, diferentes mecanismos de opresión, que reconocen en la esclavitud un antecedente fundamental, se materializan en el cotidiano capitalista desde la génesis del mismo.

La coexistencia compleja de los mecanismos de explotación y opresión se tornan, de esta manera, aspectos sustanciales para explicar los fundamentos de la "cuestión social" en las sociedades contemporáneas. Asimismo, tal complejidad se profundiza cuando distintos mecanismos de opresión convergen y refuerzan procesos de explotación.

Frente a esta realidad, distintas aproximaciones realizadas tienden a escindir unos procesos de otros, circunscribiendo el horizonte explicativo en los mecanismos particulares de opresión, obturando el proceso de generalización hacia aquellas determinaciones que permiten comprender su funcionalidad en la explotación capitalista. 
Ante estas aproximaciones, recuperando la vigencia de la categoría "cuestión social", las líneas precedentes han procurado identificar las características centrales que ésta tiene en la sociabilidad burguesa, donde la acumulación originaria y la ley general de acumulación capitalistas identificadas por Marx son aspectos sustanciales. En consonancia, se han establecido los trazos generales que permiten vincular dos mecanismos de opresión de las sociedades contemporáneas con dichos procesos de acumulación, demostrando como desde su génesis el patriarcado y la conquista de América han sido partes sustanciales dialécticamente articulados con la nueva totalidad naciente.

Recebido em 22/2/2016 — Aprovado em 31/5/2016

\section{Referencias bibliográficas}

CAMPAGNE, F. Feudalismo tardío y revolución. Buenos Aires: Prometeo, 2005.

CIRIZA, A. Estudio introductorio: retornar a Engels. Sobre las relaciones entre marxismo y feminismo. En: ENGELS, F. El origen de la familia, la propiedad privada y el Estado. Buenos Aires: Ediciones Rosa Luxemburg, 2007.

D'ATRI, A. Pan y Rosas: pertenencia de género y antagonismo de clase en el capitalismo. Buenos Aires: Las Armas de la Crítica, 2004.

EISENSTEIN, Z. Algunas notas sobre las relaciones del patriarcado capitalista. En: Patriarcado capitalista y socialismo feminista. México: Siglo XXI, 1980.

ELLIOT, J. H. La conquista española y las colonias de América. En: BETHELL, L. Historia de América Latina. Cambridge/Barcelona: University Press/Critica, 1990. . España y su mundo: 1500-1700. Madrid: Alianza Editorial, 1990b.

FEDIRICI, S. Calibán y la bruja: mujeres, cuerpo y acumulación originaria. Buenos Aires: Tinta Limón, 2015.

GIDDENS, A. El capitalismo y la moderna teoría social. Barcelona: Labor, 1994.

GOLDMAN, W. Z. La mujer, el Estado y la revolución. Política, familia y vida social soviéticas: 1917-1936. Buenos Aires: Ediciones IPS, 2010. 
HILL, C. La revolución inglesa de 1640. Barcelona: Anagrama, 1977.

HILTON, R. Siervos liberados: los movimientos campesinos y el levantamiento inglés de 1381. Madrid: Siglo XXI, 1978.

HILTON, R. Conflicto de clases y crisis del feudalismo. Barcelona: Crítica, 1988.

HOBSBAWM, E. El mundo del trabajo. Estudios históricos sobre la formación y la evolución de la clase obrera. Barcelona: Crítica, 1987.

. En torno a los orígenes de la revolución industrial. Madrid: Siglo XXI, 1988.

. La era de la revolución. 1789-1848. Buenos Aires: Crítica, 2007.

. La era del imperio. 1875-1914. Buenos Aires: Crítica, 2007b.

IAMAMOTO, M. Servicio Social y División del Trabajo. São Paulo: Cortez, 1997.

. La cuestión social en el capitalismo. Revista Temporalis, n. 3. Porto Alegre: ABEPSS, 2004.

. Serviço social em tempo de capital fetiche: capital financeiro, trabalho e questão social. São Paulo: Cortez, 2007.

IANNI, O. Esclavitud y capitalismo. México: Siglo XXI, 1976.

JIMÉNEZ ABOLLADO, F. L. Implantación y evolución de la encomienda en la provincia de Tabasco, 1522-1625. Anuario de Estudios Americanos, Sevilla, Escuela de Estudios Hispanoamericanos de Sevilla, v. 57, n. 1, 2000.

JOHNSON, H. B. La colonización portuguesa del Brasil, 1500-1580. En: BETHELL, L. Historia de América Latina. Cambridge/Barcelona: Cambridge University Press/Crítica, 1990.

KLEIN, H. Los esclavos africanos. En: CASTILLERO CALVO, A.; KUETHE, A. Historia general de América Latina: consolidación del orden colonial. Madrid: Unesco, 2007. v. III/2.

LERNER, G. La creación del patriarcado. Barcelona: Crítica, 1990.

LESSA, S. Abaixo a família monogâmica! São Paulo: Instituto Lukács, 2012.

MACLEOD, M. J. Aspectos de la economía interna de la América española colonial: fuerza de trabajo, sistema tributario, distribución e intercambios En: BETHELL, L. Historia de América Latina. Cambridge/Barcelona: Cambridge University Press/Crítica, 1990. t. III. 
MALLARDI, M. Cuestión social y cotidiano: Implicancias objetivas y subjetivas de la sociabilidad capitalista. La Plata, Argentina: Dynamis, 2015.

MALVIDO, E. La epidemiología, una propuesta para explicar la despoblación americana. En: N. SÁNCHEZ ALBORNOZ, N. (Coord.). ¿Epidemias o explotación? La catástrofe demográfica del Nuevo Mundo. Revista de Indias, Dossier. Madrid, v. LXIII, n. 227, enero/ abril 2003.

MARX, C. El capital. Buenos Aires: Siglo XXI, 2009a. t. I, v. I. . El capital. Buenos Aires: Siglo XXI, 2009b. t. I, v. II. . El capital. Buenos Aires: Siglo XXI, 2009c. t. I, v. III.

MEILLASSOUX, C. Mujeres, graneros y capitales. México: Siglo XXI, 1985.

MÖRNER, M. Economía rural y sociedad colonial en las posesiones españolas en Sudamérica. En: BETHELL, L. Historia de América Latina. Cambridge/Barcelona: Cambridge University Press/Crítica, 1990. t. III.

NETTO, J. P. Marxismo e família. Notas para uma discussão. En: AZEVEDO, M.; GUERRA, M. A. (Orgs.). Infância e violência doméstica: fronteiras do conhecimento. São Paulo: Cortez, 1997.

. Reflexiones en torno a la cuestión social. En: VVAA Nuevos escenarios y práctica profesional: una mirada crítica desde el Trabajo Social. Buenos Aires: Espacio, 2002.

. Capitalismo monopolista y servicio social. São Paulo: Cortez, 2002 b.

. Cinco notas a propósito de la Cuestión Social. En: BORGIANNI; GUERRA; MONTAÑO (Orgs.). Servicio Social crítico: hacia la construcción del nuevo proyecto ético-político profesional. São Paulo: Cortez, 2003.

PIMENTEL, E. Uma nova questão social? Maceió: UFAL, 2007.

QUARTIM DE MORAES, M. L. Pós-modernismo, marxismo e feminismo. En: Margem Esquerda, São Paulo: Boitempo, 2003. (Ensaios marxistas; n. 2.)

SAFFIOTI, H. I. B. Quem tem medo dos esquemas patriarcais de pensamento? Crítica Marxista, São Paulo, Boitempo, n. 11, 2000.

SCHWARTZ, S. B. Brasil colonial: plantaciones y periferias: 1580-1750. En: BETHELL, L. Historia de América Latina. Cambridge/Barcelona: Cambridge University Press/Crítica, 1990. t. III. 
SILVA, N. C. Pereira da. Questão social e questão racial no Brasil: a visão de Octavio Ianni. Em Pauta, Rio de Janeiro, Faculdade de Serviço Social da Universidade do Estado do Rio de Janeiro, v. 6, n. 23, 2009.

SOUZA, T. Martins de Santos. Patriarcado e capitalismo: uma relação simbiótica. Temporalis, Brasília, ano 15, n. 30, jul./dez. 2015.

THOMPSON, E. La formación de la clase obrera en Inglaterra. Madrid: Capitán Swing, 2012.

WACHTEL, N. Los indios y la conquista española. En: BETHELL, L. Historia de América Latina. Cambridge/Barcelona: Cambridge University Press/Crítica, 1990.

WILLIAMS, E. Capitalismo y esclavitud. Madrid: Traficantes de Sueños, 2011.

YOUNG, I. Marxismo y feminismo, más allá del matrimonio infeliz (una crítica al sistema dual). El Cielo Por Asalto, año II, n. 4, otoño/invierno 1992. 